Belleri, A., Schoettler, M.J., Restrepo, J.I., Fleischman, R.B.

Dynamic behavior of rocking and hybrid cantilever walls in a precast concrete building (2014) ACl Structural Journal, 111 (3), pp. 661-671. 
Andrea Belleri, Matthew J. Schoettler, José I. Restrepo and Robert B. Fleischman

6 Biography:

Andrea Belleri is a post-doctoral fellow at the Department of Engineering at the University of Bergamo in Bergamo, Italy. He received his PhD from the University of Trento, Italy. He has

9 interests in performance-based seismic design of precast and reinforced concrete structures.

10 Matthew J. Schoettler is a post-doctoral scholar in the Department of Civil and Environmental

11 Engineering at the University of California at Berkeley. He received his $\mathrm{PhD}$ from the University of

12 California, San Diego. His research activities include the seismic design and retrofit of precast and 13 reinforced concrete bridges and buildings.

14 José I. Restrepo, FACI, is a Professor in Structural Engineering at the University of California at 15 San Diego. He received his Bachelor in Civil Engineering from Universidad de Medellín in 16 Colombia; and $\mathrm{PhD}$ from the University of Canterbury in Christchurch, New Zealand. He has research and educational interests in structural concrete, in particular in seismic design of reinforced and precast/prestressed buildings, bridges and marine structures. Professor Restrepo is a member of

19 ACI Committee 550 (Precast Concrete). He is also a past recipient of the Chester Paul Siess Award 20 for Excellence in Structural Research.

21 Robert B. Fleischman is an Associate Professor for the Department of Civil Engineering and 22 Engineering Mechanics at the University of Arizona, Tucson, Arizona. His research interests 23 include seismic behavior of precast concrete systems and floor diaphragms. 
2 This paper discusses the dynamic response of precast, post-tensioned, rocking and hybrid cantilever

3 walls that provided lateral force resistance to a three story precast concrete building built at half-

4 scale. The building was subjected to extensive shake table testing on the NEES Large High-

5 Performance Outdoor Shake Table at the University of California, San Diego. The tests provided a

6 landmark opportunity to observe the dynamic response of this type of lateral force resisting system.

7 Excellent performance was observed overall. Comparison between the assumptions made during 8 the wall's design and the experimental results allowed the validation of the presented design 9 procedure and of the reinforcement detailing in the critical region at the base of the walls.

11 Keywords: hybrid wall; rocking wall; lateral force resisting system; precast concrete; post-tension; 12 seismic design; shake table tests.

In recent years, rocking and hybrid cantilever walls have been developed as lateral force resisting systems for buildings. ${ }^{1-10}$ These cantilever walls are an extension of the hybrid coupled wall system developed under the PRESSS program. ${ }^{1111}$ The main advantages of rocking and hybrid walls, detailed appropriately, are the elimination of residual drifts and the minimization of structural damage, which are desirable features for resilient structures. They make use of gravity loading or gravity loading supplemented with unbonded post-tensioned tendons to ensure self-centering response. The toes in these walls can be explicitly detailed to enable rocking without significant structural damage and at a minimal cost increase.

23 A rocking wall displays a nonlinear elastic response under lateral loading. A distinct stiffness reduction is observed in the monotonic lateral force-displacement response of these walls once uplifting of the wall base takes place, see Fig. 1(a). In theory, the response is elastic as it follows the same nonlinear force-displacement path during loading and unloading, although in practice 
1 some energy dissipation occurs due to hysteresis in the concrete at the compressed toes in the wall.

2 Compared to conventional monolithic or emulative precast solutions, the lack of energy dissipation

3 in rocking walls could lead to greater system displacements and to a higher number of large

4 displacement peaks. ${ }^{2,5}$

5 To overcome the inherently low energy dissipation, hybrid walls expand on the rocking wall

6 concept. Energy dissipators are placed in strategic locations in these walls. Like rocking walls,

7 hybrid walls are detailed to display a self-centering response and improved resilience to structural

8 damage. In contrast with rocking walls, hybrid walls are explicitly designed for energy dissipation,

9 which is often hysteretic, but can also be of a viscous type, see Fig. 1(b).

10 A review of the literature indicates that the majority of tests on precast concrete rocking and hybrid

11 walls have been conducted quasi-statically ${ }^{4,8,12}$ and the design recommendations derived

12 accordingly. ${ }^{3,4,6,7,9}$ Marriott et al. ${ }^{13}$ reported shake table tests on single rocking and hybrid walls.

13 These consisted of a single precast panel connected at the top to a suspended mass. Different

14 devices were used to provide energy dissipation: (i) external, mild steel, tension-compression-

15 yielding, buckling restrained bars, (ii) viscous dampers, and (iii) a combination of the two previous

16 devices. All tests displayed excellent performance. To the authors' knowledge, only Toranzo et al. ${ }^{5}$

17 investigated the interaction between rocking walls and the rest of the structure. These researchers

18 carried out shake table tests on a three-story scaled structure in which non post-tensioned confined

19 masonry rocking and hybrid walls acted as the lateral force resisting system.

20 The test program reported herein presents key results of the dynamic response of rocking and

21 hybrid cantilever walls to input ground motion. These walls provided the primary lateral force

22 resistance to a three story, oblong, precast concrete building built at half-scale and tested

23 extensively on the Network for Earthquake Engineering Simulation (NEES) Large High-

24 Performance Outdoor Shake Table at the University of California at San Diego (Fig. 2). ${ }^{14}$ 
2 This paper highlights the excellent seismic performance of precast, post-tensioned, rocking and

3 hybrid cantilever walls in a complete building system. These dynamic, shake table tests are unique

4 as they are the first ever from a building whose lateral force is primarily resisted by this type of

5 system. Emphasis is made on (i) the overall dynamic response of rocking and hybrid cantilever

6 walls; (ii) the influence of the higher modes of response and impact during the gap closure on the

7 wall demands; and (iii) the strain distribution in the confined concrete wall toes. Finally, the paper

8 compares measured and expected wall responses.

\section{EXPERIMENTAL INVESTIGATION}

\section{Wall Design Objectives}

11 A three story precast concrete building was built as the capstone test ${ }^{14}$ of a large research project

12 funded by a number of organizations and companies that supported the development of a seismic 13 design methodology for precast concrete diaphragms. ${ }^{15}$ Because of their self-centering 14 characteristics and expected minimal structural damage, precast post-tensioned cantilever walls, acting in rocking or hybrid mode, were an advantageous choice for the lateral force resisting system in a building that would be subjected to multiple large intensity ground motions. The building, termed the model structure hereafter, had a $17.07 \mathrm{~m}$ long by $4.88 \mathrm{~m}$ wide $(56 \mathrm{x} 16 \mathrm{ft})$ rectangular plan, see Fig. 3. Floor to floor heights were $1.98 \mathrm{~m}(6.5 \mathrm{ft})$. Two identical $2.44 \mathrm{~m}(8 \mathrm{ft})$ wide by $7.01 \mathrm{~m}(23 \mathrm{ft})$ tall by $0.20 \mathrm{~m}(8 \mathrm{in}$.$) thick precast walls were placed at the North and South ends of$ the model structure as the primary lateral force resisting system, see Figs. $\mathbf{3}$ and $\mathbf{4}$. In these walls,

21 the post-tensioning force could be adjusted before a test. This allowed tuning of the wall momentrotation response to the Design Basis Earthquake (DBE) requirements for three geographical

23 locations investigated, each with a distinct seismic hazard. These locations were downtown 24 Knoxville, Tennessee, (low seismic hazard); downtown Seattle, Washington, (intermediate seismic hazard); and downtown Berkeley, California, (high seismic hazard and near fault conditions). After 
1 completion of the DBE tests for the three sites, the building was subjected to the Maximum

2 Considered Earthquake (MCE) for the Berkeley site.

3 The walls were designed to meet the DBE demands for the three different geographical locations,

4 with the highest demands imposed by the Berkeley site. Schoettler at al. ${ }^{14}$ discuss the seismic

5 design of the entire building. The general guidelines proposed by Restrepo and Rahman ${ }^{4}$ were used

6 in the design and detailing of the walls.

\section{$7 \quad$ Design and Construction}

8 To ensure a stable hysteretic response and geometrical stability of the wall, ${ }^{4}$ the neutral axis depth,

$9 c$, was restricted to within fifteen percent of the wall length at the Berkeley DBE. Accordingly, the

10 concrete in the wall toes was confined about $300 \mathrm{~mm}(1 \mathrm{ft})$. The confinement reinforcement was

11 designed to ensure a 25 millistrain ultimate compressive strain capacity in the confined concrete

12 core according to the design recommendation ${ }^{4}$ of providing a compressive strain of the confined

13 wall toe not less than the wall base rotation design value $\left(\theta_{w, d e s}\right)$, taken as 25 milliradian for the

14 Berkeley DBE.

15 The confined concrete parameters ${ }^{\mathrm{a}}$ were calculated with the model proposed by Mander et al. ${ }^{16}$ The 16 extreme ends of the wall toes were armored with $229 \mathrm{~mm}$ (9 in.) long by $178 \mathrm{~mm}$ (7 in.) wide by 13 $17 \mathrm{~mm}$ (0.5 in.) thick embed steel plate, see Figs. 4 and 5. Four \#6 (19 mm diameter) 356 mm (14 in.) 18 long deformed bars were welded to these embed plates. The main purpose of these vertical plates 19 was to protect the concrete toes from impact against shear keys set back $3 \mathrm{~mm}$ (0.12 in.) from the 20 wall toe to limit unanticipated shear sliding. These embed plates essentially replaced the concrete 21 cover that could spall as a result of the expected high compressive strains there as a result of 22 rocking. These plates also provided additional confinement to the core concrete. In addition to 23 confinement, the wall toes were detailed with $10 \# 5$ (15.9 mm diameter) ASTM A706 headed 24 longitudinal bars. The main purpose of these bars was to share the compressive force with the

\footnotetext{
${ }^{\mathrm{a}}$ Test wall confined and un-confined region details are listed in Table A-1 found in Appendix A
} 
1 concrete, thus reducing the neutral axis depth. Heads on these bars enhanced the bar compressive

2 force transfer through the bedding mortar into the footing.

3 Transverse hoops spaced at $200 \mathrm{~mm}$ (8 in.) were provided as shear reinforcement and based on

4 recommendations by Perez et al. ${ }^{8}$ to prevent separation of the confined region from the region

5 containing post-tensioning and ungrouted energy dissipation ducts. These hoops consisted of \#3

6 (9.5 mm diameter) transverse hoops spanning the full wall length and provided continuity between

7 these regions.

8 Prior to erection of the precast wall, the wall and footing interface surfaces were roughened with a

9 rotary hammer to approximately $3 \mathrm{~mm}\left(0.12 \mathrm{in}\right.$.) to improve shear transfer. The grout ${ }^{\mathrm{b}}$ beneath the

10 wall was prepared in a concrete mixer to ensure even distribution of polypropylene fibers provided

11 at a dose of $0.89 \mathrm{~kg} / \mathrm{m}^{3}$ (1.5 lb per cubic yard) to increase toughness. ${ }^{11}$ Particular care was taken

12 during erection with the position of $75 \mathrm{~mm}$ x $75 \mathrm{~mm}$ (3 in. x 3 in.) Nylon shim stacks by placing

13 them outside the neutral axis depth calculated for the DBE. These shim stacks provided $25 \mathrm{~mm}$ (1

14 in.) of clearance between the foundation and the wall for the bedding mortar that was placed after

15 plumbing the wall. The $25 \mathrm{~mm}$ (1 in.) thick, $2438 \mathrm{~mm}$ (96 in.) long by $279 \mathrm{~mm}$ (11 in.) wide grout

16 pad extended $38 \mathrm{~mm}$ (1.5 in.) beyond the wall width. $19 \mathrm{~mm}$ x $25 \mathrm{~mm}$ x $203 \mathrm{~mm}(0.75 \mathrm{in} . \mathrm{x} 1$ in. $\mathrm{x}$

178 in.) Styrofoam blockouts restricted grout from beneath the embed plates at the toes of the wall to

18 prevent bearing. After erecting the wall, shear keys were welded to embed plates in the footing to

19 limit unanticipated wall shear sliding. Shear keys at either end of the wall consisted of two steel

20 angles strengthened with gusset plates and were $3 \mathrm{~mm}$ (0.12 in.) clear of the wall's embed plate, see

21 construction sequence in Fig. 4. In addition to shear sliding, the angles were designed to restrain

22 out-of-plane motion of the wall. To accomplish this, a $28 \mathrm{~mm}$ (1.10 in.) gap between the two angles

23 accommodated a $25 \mathrm{~mm}$ (1 in.) square by $51 \mathrm{~mm}$ (2 in.) high tab welded to the wall's embed plate.

24 This configuration allowed vertical uplift of the wall, but lateral movement would cause the tab to

25 engage a shear key.

\footnotetext{
${ }^{\mathrm{b}}$ The grout and wall material properties are listed in Table A-2 found in Appendix A
} 
1 A large percentage of the restoring force in these walls was provided by unbonded post-tensioning.

2 Minor sources of restoring force were the wall self-weight and the restoring force of the energy

3 dissipation bars, when they were used. It is worth noting that because of the diaphragm-to-wall

4 connection, as is described below, no gravity load was carried by the walls except their own self-

5 weight. Post-tensioning consisted of two tendons. Each tendon had five $12.7 \mathrm{~mm}$ (0.5 in.) diameter

6 low-relaxation strands placed through $50 \mathrm{~mm}$ (2 in.) diameter vertical ducts, each located at 305

$7 \mathrm{~mm}(1 \mathrm{ft}$.$) from the wall centerline, see Fig. 5. Each strand was anchored with three-wedge anchors$

8 at their ends. The tendons were stressed at the top of the wall by hallow core jacks that were left in

9 place throughout testing. This allowed the stressing force to the adjusted prior to each test.

10 Furthermore, because each jack was outfitted with a pressure gage, the force variation in each

11 tendon during dynamic response was monitored.

12 For tests attributed to the seismicity of Knoxville, the total prestressing force in each wall was set at $13472 \mathrm{kN}$ (106 kips), whereas for the more demanding sites of Seattle and Berkeley it was increased 14 to $642 \mathrm{kN}$ (144 kips). Therefore, the average strand tensile stress of $0.26 f_{p u}$ for the Knoxville test 15 and $0.35 f_{p u}$ for the Seattle and Berkeley tests.

16 The foundation beam for each wall was cast with $5 \# 7$ (22 mm diameter) single-headed $2260 \mathrm{~mm}$ 17 (90 in.) long vertical bars to act as hysteretic energy dissipators. Fig. 5 depicts the location of 18 energy dissipators $\mathrm{ED}_{1}, \mathrm{ED}_{2}$ and $\mathrm{ED}_{3}$ in the cross-section of the wall. The dissipators protruded $191346 \mathrm{~mm}$ (53 in.) from the foundation. To accommodate these dissipators, the base of the precast 20 walls incorporated five $66 \mathrm{~mm}$ (2.6 in.) diameter by $1524 \mathrm{~mm}$ (60 in.) long corrugated steel ducts. 21 The dissipators were to be selectively grouted prior to a specific test. The central dissipator, 22 depicted in Fig. 5 as $\mathrm{ED}_{1}$, was intended for use in the Knoxville test, but ultimately the wall in this 23 test was configured as rocking. Placing energy dissipators $\mathrm{ED}_{2}$ and $\mathrm{ED}_{3}$ in each wall, but not 24 grouting them simultaneously, allowed pairs of bars to be activated as needed. This was 25 incorporated as a repair strategy to replace a damaged bar by grouting the adjacent one. An 26 efficient, cost effective procedure to eliminate a damaged or suspect bar was to core drill 
1 horizontally a $44 \mathrm{~mm}$ (1.75 in.) hole through the grout pad and wall base to cut through the bar.

2 Energy dissipators $\mathrm{ED}_{1}$ and $\mathrm{ED}_{2}$ were debonded over 1.7 times their diameter, $d_{b}$, within the

3 footing, while energy dissipator $\mathrm{ED}_{3}$ was debonded over $5.7 d_{b}$, see Fig. 5 . The outermost

4 dissipators were debonded 5.7 bar diameters to account for their greater distance from the neutral

5 axis expected in the Berkeley DBE test. Debonding was achieved with rubber mastic tape. This

6 debonded length, $l_{d e b_{-} E D}$, was calculated to limit the tensile strain to $2 / 3$ of the strain at the ultimate

7 tensile strength, $\varepsilon_{U T S},{ }^{44}$ when the wall gap opening reaches the Berkeley DBE design value, $\theta_{w, \text { des }}=$

825 milliradian. This calculation, which accounts for strain penetration outside the debonded region

9 of an additional $12 d_{b}$ of equivalent uniform strain, is given by

$10 \quad l_{\text {deb_ED }} \geq \frac{3}{2} \frac{l_{E D}-c}{\varepsilon_{U T S}} \theta_{w, d e s}-12 d_{b}$

11 where $l_{E D}$ is energy dissipator distance from the wall edge and $c$ is the neutral axis depth.

12 For the Knoxville test, the walls were configured as rocking and were post-tensioned only. That is,

13 the energy dissipation bars that protruded from the foundation were left ungrouted for the tests

14 considering this site. In contrast, for the other tests, the walls were configured as hybrid. To

15 provide hysteretic energy dissipation the two bars closest to the wall centerlines were grouted into

16 the walls with a proprietary pumpable grout. Under this configuration, the energy dissipation index

17 defined by Rahman and Restrepo ${ }^{3}$ was $\Lambda=0.258^{\mathrm{c}}$.

18 The wall-to-floor connection consisted of seven $19 \mathrm{~mm}$ (0.75 in.) diameter threaded inserts fitted

19 inside a vertical slotted insert, which only allowed horizontal shear transfer ${ }^{14}$, see Fig. 5. A capacity

20 based design accounted for the capacity of the shear critical joint at each floor, but allocated the

21 same number of connectors at each floor. A strength reduction factor of 0.75 was used with the 22 connector's nominal shear strength. These inserts were placed to allow unrestricted vertical 23 movement between the wall and the floors, because wall uplift was expected as a result of rocking.

\footnotetext{
${ }^{\mathrm{c}}$ A complete list of symbols used in the paper is found in Appendix B
} 
1 This detail avoided the introduction of out of plane forces in the floor, which could compromise the

2 floor-to-wall shear transfer mechanism.

3 Test sequence and instrumentation layout

4 The test structure was subjected to 16 ground motions of increasing intensity. Of these, four are

5 presented. Input motions were selected for three sites in the United States representing low

6 (Knoxville), moderate (Seattle) and high (Berkeley) seismic hazards. Historical records were

7 selected and scaled to represent a DBE for the Knoxville site (KNX), a DBE for Seattle (SEA), a

8 DBE for Berkeley (BER), and an MCE for Berkeley (MCE-BER). Because the main focus in these

9 tests was the behavior of the diaphragms, mass substitution was not provided in the model, so

10 similitude was only achieved by scaling of input ground motions. The horizontal acceleration field

11 was amplified by 1.855 to achieve the desired horizontal inertial forces and the ground motions

12 were compressed in time by 1.855. Fig. 6 plots the response spectra for five percent damping of the

13 feedback acceleration recorded on the shake table for these four tests.

14 The sequence of the input ground motions presented was KNX, SEA-1, SEA-4, BER and MCE15 BER, which resulted in increased demands with the progression of the motions. The designations “161 " and "-4” after SEA indicate the first and fourth trials of this input motion. The results of MCE17 BER are reported up to wall post-tensioning strands failure.

18 The structure's dynamic response was recorded by a dense array of sensors. Sensors were deployed 19 on the structure to monitor accelerations, displacements or deformations, strains, and pressures.

20 Fig. 7 identifies sensor types and locations deployed on the North wall of the building.

TEST RESULTS AND DISCUSSION

\section{Overall Response}

24 The overall wall response during the simulated earthquake tests was consistent with expectations.

25 During the KNX test, no damage was observed. The wall post-tensioning force allowed minor uplift 26 of the rocking walls. In this test, no energy dissipators were present (i.e., the bars were not grouted) 
1 resulting in a nonlinear elastic response. This test was repeated with similar results not presented.

2 For the SEA tests, two energy dissipator bars were grouted in each wall resulting in a hybrid wall

3 configuration. Performance of the wall was as expected during SEA-1 with no cracks, but early in

4 the test a diaphragm tension chord failure occurred at midspan of the third floor prompting repair

5 and re-testing. After two additional trials of this test without damage in the wall but repeated

6 diaphragm chord failures, a successful test, SEA-4, was completed. Only minor bond split cracks

7 developed along the grouted ducts containing the energy dissipation bars at this stage of testing.

8 During the BER test, very limited flaking of the concrete was observed in the extreme compressive

9 fiber at the toes of the wall. In this test, a ten percent drop in post-tensioning force occurred in the

10 South wall. This change, corresponding with the fracture of a single post-tensioning strand, did not

11 significantly affect the results of this test but compromised the subsequent MCE-BER test. The

12 strand failure occurred at an average strand stress of $0.45 f_{p u}$ and was likely a result of the method

13 employed to seat and stress the tendons: the five strands in tendon group were simultaneously

14 seated with hollow-core post-tensioning jacks rather than individually seating each strand, as is

15 done in practice. This method resulted in uneven wedge seating and likely an uneven distribution of

16 tendon force. It has been recently shown ${ }^{17}$ how the loading conditions affect the behavior of

17 unbounded post-tensioning strand-anchorage systems leading to anticipated strand failure, for this

18 reason it is recommended to grout the strand duct ends after post-tensioning.

19 In this paper the dynamic response of the North wall is presented. The behavior of South wall was

20 similar to the North wall, although slightly different response was recorded due to torsion in the

21 building and to the South wall strand failure during the BER test. Demands were, in general, larger

22 in the North wall. The results are presented in dimensionless terms to facilitate their interpretation

23 in model and prototype terms.

24 Wall base shear and base moment

25 Wall base shear and base moment demands were computed from the floor forces attributed to each 26 wall. All forces were calculated from the array of accelerometers distributed across each floor and 
1 their tributary mass following Newton's second law. All the data presented in the paper has been

2 low-passed at $100 \mathrm{~Hz}$ with a steep 5000-order FIR filter.

3 Horizontal shear forces transferred to the walls from the floors were computed assuming a pinned 4 connection between the floors and walls. This simply supported end condition permitted direct 5 calculation of floor forces from inertial forces. Column and beam weights were lumped in the 6 tributary weight of the floor. This distribution neglects the contribution of system shear and system 7 moment resisted by the ten gravity columns. Analytical estimates found the columns contribute 8 24\% (DBE-KNX), 21\% (DBE-SEA), 16\% (DBE-BER) to the system shear resistance and 12\% 9 (DBE-KNX), 9\% (DBE-SEA), and 8\% (DBE-BER) to the system overturning moment resistance at 10 peak response.

11 Wall base shear was computed as the summation of floor forces at each level, and the base moment 12 demand accounted for the elevation of the level above the foundation. Wall base moment and base 13 shear are shown in Fig. 8 (KNX tests with a different scaling for sake of clarity) as a function of the wall base rotation, evaluated from three vertical displacement transducers placed at the wall base (Fig. 7). P-Delta moments were neglected due to small roof drift ratios and a lack of similitude in the vertical acceleration field.

17 The nonlinear elastic response typical of a system with rocking walls is evident in the response of 18 the building during the KNX test, where a maximum 3.2 milliradian rotation occurred at the wall base. The SEA-1, SEA-4, and BER tests present the "flag-shape" hysteretic response typical of a system with hybrid walls, with a maximum wall base rotation computed as 5.7, 8.7, and 19.2 21 milliradian, respectively.

In Fig. 8 the idealized bilinear response of rocking and hybrid walls as proposed by Restrepo and 23 Rahman ${ }^{4}$ is shown. Points defining the curve, apparent yield point $\left(\theta_{y}, M_{n}\right)$ and yielding of critical 24 tendon $\left(\theta_{0}, M_{0}\right)$, are functions of the energy dissipation index $\Lambda$ and listed in Table 1 . The bilinear 25 idealization gives a good approximation for the envelope of the response, especially in the case of rocking walls (KNX) and initial cycle of SEA-1. In the case of hybrid walls, the backbone curve is 
1 only valid for one cycle of tensile yielding, subsequent cycles have reduced stiffness due to the

2 Bauschinger effect and compression in the energy dissipation bars. This results in a vertical force

3 that reduces the net compressive force across the joint until base rotation is sufficient to overcome

4 the compressive energy dissipator force. The observed hybrid wall response (SEA-1, SEA-4, BER)

5 is not as stiff as predicted for the aforementioned reason, but the post-elastic envelope is well-

6 predicted. In both cases, rocking and hybrid wall, the idealized curve does not capture the dynamic

7 wall response characterized by higher mode contributions. These fluctuations are also found in the

8 wall base shear demand where they reduce the system effective height, defined as the ratio between

9 the wall base moment and base shear. This relationship (Fig. 9) identifies the elevation of the

10 resultant shear force, and is provided when the base moment or shear is greater than $90 \%$ of the

11 peak demand in the respective test. In each of the tests presented, the system effective height

12 deviates significantly from the height anticipated by a force distribution based on the first mode

13 response as obtained from the equivalent lateral force procedure. Lower values indicate the

14 contribution of higher modes of vibration.

15 The peaks in the wall base moment and base shear demand histories at times near gap closure are 16 related to horizontal acceleration spikes arising when the wall base gap closes (Fig. 10). The 17 acceleration spikes initiate in the wall and propagate to the adjacent precast floor units with values 18 higher for upper floors and decreasing from the wall to the floor center.

19 This phenomenon is associated to the stiffness change typical of elastic bilinear and flag shape 20 hysteresis and it has been previously noted in numerical simulations ${ }^{18,19}$ and measured in tests. ${ }^{5,20}$ 21 Wiebe and Christopoulos ${ }^{19}$ explained the acceleration spikes examining a two degrees of freedom 22 system and developed a closed form mathematical solution to characterize its response: acceleration 23 spikes are expected from nonlinear springs that are initially nearly rigid, particularly when those 24 springs change from low stiffness to high stiffness while moving at a high velocity, which is the 25 case of the rocking and hybrid walls considered here. 
1 A physical explanation of the origin of the acceleration spikes is found considering the momentum

2 associated with the floors' velocities and wall rotational velocity and system lateral stiffness. When

3 the displaced system moves back and crosses its initial, un-deformed position, the floors and walls

4 have maximum rotational velocity. At the same time, the wall gap is closing, which causes the wall

5 to regain much of its initial lateral stiffness. Therefore, when the system is approaching its rest

6 position, the walls, now with high lateral stiffness, provide an obstacle to the horizontal movements

7 that generate a horizontal impulse and the horizontal acceleration spikes recorded in the 8 experimental tests.

9 The spikes are influenced by rotational velocity and by the combined lateral stiffness of the walls 10 and floors. The spikes increase in magnitude with increasing velocity and stiffness. However, 11 determining their coupled influence is not straightforward in the structural system considered, 12 because the lateral stiffness increases at lower floors while the horizontal velocity, from rigid wall 13 rotation and rotational velocity, increases at upper floors.

14 Energy dissipation bars in the hybrid wall system helped reduce the magnitude of the horizontal acceleration spikes. Peak wall accelerations were similar in the KNX test, without energy dissipation bars, and BER test, with energy dissipation bars, despite lower seismic demands in the

17 former. The peak horizontal wall accelerations in the SEA (with energy dissipation bars) tests were 18 lower than those in the KNX test despite increased seismic demands. The same qualitative 19 reduction was previously observed by Toranzo et al. ${ }^{5}$ on rocking walls with and without energy dissipation. This can be attributed to the increase of hysteretic energy absorption and the change to 21 system's lateral tangential stiffness when energy dissipation is incorporated. Without 22 supplementary energy dissipation devices, there is an increased ratio between the system lateral 23 tangential stiffness when the base gap is closing and when it is closed, which is consistent with 24 previous findings. ${ }^{19}$ Horizontal acceleration spikes are not present in traditional reinforced concrete 25 walls because the lateral tangential stiffness does not exhibit a drastic change when the wall crosses 26 its initial position. 
1 The main consequence of the horizontal acceleration spikes observed experimentally is an increase

2 of the base shear demand at lower than expected wall base rotations, as it will be clear from the

3 evaluation of the required coefficient of friction discussed later in the paper. Therefore, it is

4 important to evaluate the base shear demand and capacity including higher mode effects at this

5 often overlooked limit state, especially if relying on shear friction. When the gap opens, elongation

6 of the post-tensioning tendons increases the compressive force across the joint and thus increases

7 the shear friction capacity. However, shear friction capacity is lowest when the gap closes because

8 the post-tensioning force is at minimum and, for hybrid walls, the vertical force in the energy

9 dissipation bars reduces the compressive force across the joint. It is recommended this

10 consideration be accounted for in the design of hybrid walls.

11 Another source of reduced shear friction capacity is the wall vertical accelerations at the wall

12 centerline generated when the gap closes (Fig. 11). Acceleration spikes occur with vertical impact

13 of the wall on the foundation when the gap closes. These spikes show increasing magnitude with

14 increasing wall rotational velocity at impact, which is related to the gap opening and vertical restoring force in the wall. For the test specimen, the acceleration spikes propagate from the bottom to the top of the wall without being transmitted to the adjacent floor panels due to the slotted wallto-floor connection. When acting upward, the accelerations reduce the axial force across the joint 18 decreasing the shear friction capacity. According to the test results, the maximum total vertical 19 acceleration acting upward in the walls of the prototype structure is $-0.6 \mathrm{~g}, 0.4 \mathrm{~g}, 0.4 \mathrm{~g}$ and $1.7 \mathrm{~g}$ for the KNX, SEA-1, SEA-4 and BER test, respectively.

21 It is important to investigate the correlation between vertical and horizontal acceleration spikes 22 because they affect the shear friction capacity and the base shear demand, respectively. Fig. 12 23 shows the effect of the horizontal and vertical acceleration peaks in terms of the coefficient of 24 friction required to avoid sliding at the interface between the wall and the foundation. Approaching gap closure, the base shear demand increases and the shear friction capacity, at its minimum, oscillates due to the vertical accelerations leading to an increase of the required coefficient of 
1 friction especially for the tests with higher gap opening. Therefore, if friction is relied on as the sole

2 shear transfer mechanism at the wall base in these type of walls, it is recommended to evaluate

3 shear friction capacity and demand not only at the maximum gap opening corresponding to the

4 probable flexural strength ${ }^{7}\left(M_{p r}\right)$, but also upon closing of the wall base gap.

5 Considering the test results, this can be taken into account evaluating the shear friction capacity and

6 demand at a closed base gap for the rocking and hybrid walls. The shear friction demand at gap

7 closure during KNX, SEA-1, SEA-4 and BER test was respectively 38\%, 35\%, 29\% and 32\% of the

8 maximum shear demand during that test. The maximum shear demand can be computed, accounting

9 for dynamic amplification of the test structure, as $M_{p r} r\left(0.5 h_{w}\right)$ based on Fig. 9, leading to:

$10 V_{\text {demand }\left(\theta_{w}=0\right)}=\alpha \cdot V_{\text {demand, } \max }=\alpha \cdot M_{p r} /\left(0.5 \cdot h_{w}\right)$

11 where $\alpha$ is equal to 0.4 based on the test results.

12 The shear friction capacity is evaluated with a closed gap considering the reduction of the gravity 13 load due to the vertical acceleration spikes and reduction of net axial force due to energy dissipation 14 bars as:

$$
V_{\text {capacity }\left(\theta_{w}=0\right)}=\mu_{f} \cdot\left(F_{p 0}-F_{e d}-\left(a_{v} / g-1\right) \cdot P_{u}\right)
$$

The reduction due to vertical acceleration can be associated, based on the test results, to an upward vertical acceleration for the prototype structure $a_{v}$ varying linearly from $0 \mathrm{~g}$ to $+3.1 \mathrm{~g}$ for an expected maximum base gap opening from 0 to 20 milliradian, respectively. Further research is needed to extend the results to structures with different geometry and energy dissipation index, $\Lambda$, and to consider the effects of the vertical ground acceleration in $a_{v}$.

21 In the case of rocking and hybrid walls, an important consideration is sliding at the base of the wall due to the jointed nature of this type of construction that provides no aggregate interlock. In hybrid walls, dowel action of the energy dissipation bars should be neglected to preserve their primary function. A base shear demand greater than the sliding shear capacity leads to a slip at the base joint with detrimental effects to the energy dissipation bars that will kink and fail in subsequent cycles. Post-tensioning ducts are likely large enough to accommodate a small amount of sliding before 
1 kinking the post-tensioning strands. However, re-centering capability is lost with this deformation

2 mode so it should be avoided.

3 Wall neutral axis and confined core concrete strains

4 The experimental tests allowed two other design objectives to be investigated: those related to

5 neutral axis depth and confined core concrete strains. Fig. 13 shows the neutral axis depth,

6 evaluated from three vertical displacement transducers along the wall base, when the maximum

7 flexural moment is reached. The test results show a minimum neutral axis depth of about $11 \%$ of

8 the wall length corresponding to 20 milliradian wall base opening. This value, although lower than

9 expected, is consistent with the design objective established by Restrepo and Rahman ${ }^{4}$ (15\% $l_{w}$ ),

10 which they associated with spalling of the concrete cover leading to an increase of the neutral axis

11 depth. However, in the experiment only limited concrete flaking was observed.

12 To the authors' knowledge no experimental results are available in the literature showing directly

13 the concrete compressive strains upon rocking during dynamic testing. Only average strains 14 obtained from displacement transducer at wall toes. ${ }^{13}$ The strain distribution helps evaluate 15 assumptions made in the design process.

16 The concrete strains at the wall toes were measured by electrical foil strain gauges. The gauge size 17 was selected according to Binns and Mygind $^{21}$ in order to reduce errors arising when a gauge covers 18 only one large aggregate. A gauge length of $30 \mathrm{~mm}$ (1.18 in.) was selected based on an associated 19 error of less than $12 \%$ for a $20 \mathrm{~mm}(0.79$ in.) gauge length with a specified maximum aggregate 20 size of $9.5 \mathrm{~mm}(3 / 8 \mathrm{in}$.$) diameter.$

21 The strain pattern resulting from the shake table tests is outlined in Fig. 14. The strain value 22 considered in the design process, ${ }^{4}$ associated to the design basis earthquake BER, was 25 millistrain, 23 while the mean response of both toes in terms of maximum strain recorded during that test was 1.3 24 millistrain. This is considerably lower than expected as it is clear from Fig. 15 where the strain 25 results are compared to the equation ${ }^{4}$ adopted in the design process. 
1 The lower than anticipated concrete strain demand is associated to the design equation assumption

2 on the shortening of the compressed wall toe with a constant strain distribution over a height above

3 the foundation corresponding to the neutral axis depth, $c$. The constant strain distribution was

4 reasonably valid over the height monitored (Fig. 14), but further research is needed to quantify the

5 strain distribution in the disturbed region, approximately up to a height equal to $l_{w}$.

6 The design procedure adopted leads to an over-conservative estimate for both the strength of the

7 compressed region and its strain capacity. Therefore, it is suggested to design the confinement of

8 the compressed concrete toe in order to carry the axial load associated to failure in tension of both 9 energy dissipators and post-tensioning tendons.

\section{CONCLUSIONS}

The performance and suitability of hybrid and rocking walls as lateral force resisting elements was demonstrated under seismic loading. The damage observed in the wall after three DBE scenarios for Knoxville, TN, four repeated simulations of a DBE event for Seattle, WA, and a DBE test for Berkeley, CA, was limited to flaking at the wall toe. Unacceptable tendon performance caused by strand seating did not affect the DBE-BER test. Only minor damage to the wall toe was observed at this stage of testing. However, a subsequent MCE-BER test was compromised by this strand failure resulting in complete tendon failure in both walls, and uncontrolled wall rocking with unacceptable drift demands before impact with restraint devices. This failure highlights two important design considerations for these systems: end anchorages need further development for reliability and postearthquake inspection of the tendon condition is recommended. Strand failure was overlooked in the post-test damage documentation because of the lack of visual clues. In-situ assessment is anticipated to be costly as stressing jacks will be required to evaluate each strand post-earthquake to comply with this recommendation. For enhanced reliability of anchorages, it is recommended that duct ends be grouted after post-tensioning, which would permit full development of the tendon's ultimate capacity. 
1 The results obtained from the experimental program allow the following considerations to be made

2 regarding rocking-hybrid wall behavior. The neutral axis depth can be successfully controlled in

3 design to ensure both hysteretic response and geometrical stability. The addition of the energy

4 dissipation bars leads to the typical flag shaped moment-rotation behavior compared to the

5 nonlinear elastic response associated with the use of unbounded post-tensioning tendons. The use of

6 energy dissipation bars helps to reduce the magnitude of the horizontal acceleration spikes arising

7 when the wall base gap closes during dynamic response.

8 The wall base shear demand and capacity can be adversely affected by the dynamic interaction

9 between the wall and the building. In fact, when the wall foundation joint closes, vertical and

10 horizontal acceleration spikes arise in the wall and the horizontal spikes extend partially into the

11 floors reducing the shear friction capacity and increasing the demand, respectively. As a result, the

12 base shear demand and capacity must be checked at the gap closure; a tentative recommendation to

13 account for dynamic amplification based on test results is proposed, although further research is

14 needed. Typical recommendations ${ }^{7}$ call for base shear evaluation at maximum gap opening, when

15 the shear friction capacity is maximum due to the increase of vertical force associated with post-

16 tensioning tendons elongation, but dynamic amplification and decreased shear friction capacity

17 caused by compression yielding in the energy dissipation reinforcement make for a more critical

18 scenario at gap closure.

19 The design procedure to define the wall base confined concrete core considered base rotation

20 accommodated through shortening of the wall toe with a constant strain distribution over a distance

$21 \quad c$ (neutral axis depth) above the foundation; this led to over-conservative estimates of the 22 compressed region's strength and strain capacity. It is suggested to design the confinement of the 23 compressed concrete toe in order to carry the axial load associated with failure in tension of both 24 energy dissipators and post-tensioning tendons. 
2 The authors wish to express their gratitude to the Precast/Prestressed Concrete Institute, the

3 National Science Foundation, the Charles Pankow Foundation, and the George E. Brown Jr.

4 Network for Earthquake Engineering Simulation. These organizations were the primary sources of

5 funding for the research project. The project Advisory Group is sincerely thanked for contributing

6 their expertise to the shake-table test program. Special thanks is given to Dave Dieter, Dr. Carlos

7 Blandon, Humberto Cabrera, Dan Radulescu, and the technical support staff from the Englekirk

8 Center at the University of California, San Diego for their dedication and assistance before and

9 during the tests. The opinions, findings, and conclusions expressed in the paper are those of the 10 authors and do not necessarily reflect the views of the individuals and organizations acknowledged.

\section{REFERENCES}

13 1. Kurama, Y. C., "Seismic Design of Unbonded Post-Tensioned Precast Concrete Walls with

2. Kurama, Y. C., "Hybrid Post-Tensioned Precast Concrete Walls for Use in Seismic Regions”, Supplemental Viscous Damping”, ACI Structural Journal, Vol. 97:4, 2000, pp. 648-658. PCI Journal, Vol. 47:5, 2002, pp. 36-59.

3. Kurama, Y. C., "Seismic Design of Partially Post-Tensioned Precast Concrete Walls”, PCI Journal, Vol. 50:4, 2005, pp. 100-125.

4. Restrepo, J. I., and Rahman, A., "Seismic Performance of Self-Centering Structural Walls Incorporating Energy Dissipators”, Journal of Structural Engineering, Vol. 133:11, 2007, pp.

5. Toranzo, L. A., Restrepo, J. I., Mander, J. B., and Carr, A. J., “Shake-Table Tests of Confined-Masonry Rocking Walls with Supplementary Hysteretic Damping”, Journal of Earthquake Engineering, Vol. 13:6, 2009, pp. 882-898. 
1 6. ACI ITG-5.1, “Acceptance Criteria for Special Unbonded Post-Tensioned Precast Structural Walls Based on Validation Testing”, ACI Innovation Task Group 5, 2008.

3 7. ACI ITG-5.2, "Requirements for Design of a Special Unbonded Post-Tensioned Precast Shear Wall Satisfying ACI ITG-5.1”, ACI Innovation Task Group 5, 2009.

8. Pérez, F. J., Pessiki, S., Sause, R., and Lu, L., "Lateral Load Tests of Unbonded Post-

Tensioned Precast Concrete Walls”. Special publication of large-scale structural testing, $A C I$, SP-211-8, 2003, pp. 161-182.

9. Pérez, F. J., Sause, R., and Pessiki, S., “Analytical and experimental lateral load behavior of unbonded posttensioned precast concrete walls”, Journal of Structural Engineering, Vol. 133:11, 2007, pp. 1531-1540.

10. Pennucci, D., Calvi, G. M., and Sullivan, T. J., "Displacement-Based Design of Precast Walls with Additional Dampers”, Journal of Earthquake Engineering, Vol. 13:1, 2009, pp. 40-65.

11. Priestley, M. J. N., Sritharan, S., Conley, J. R., and Pampanin, S., "Preliminary Results and Conclusions from the PRESSS Five-Story Precast Concrete Test-Building”, PCI Journal, Vol. 44:6, 1999, pp. 42-67.

12. Holden, T., Restrepo, J., and Mander, J. B., "Seismic Performance of Precast Reinforced and Prestressed Concrete Walls”, Journal of Structural Engineering, Vol. 129:3, 2003, pp.286-296.

13. Marriott, D., Pampanin, S., Bull, D., and Palermo, A., “Dynamic Testing of Precast, PostTensioned Rocking Walls Systems with Alternative Dissipating Solutions”, Bulletin of the New Zealand Society for Earthquake Engineering, Vol. 41:2, 2008, pp. 90-103.

14. Schoettler, M. J., Belleri, A., Zhang, D., Restrepo, J. I., and Fleischman, R. B., "Preliminary results of the shake-table testing for the development of a diaphragm seismic design methodology, PCI Journal, Vol. 54:1, 2009, pp. 100-124. 
1 15. Fleischman, R. B., Naito, C., Restrepo, J., Sause, R., Ghosh, S. K., Wan, G., Schoettler, M., and Cao, L., "Precast Diaphragm Seismic Design Methodology (DSDM) Project, Part 2: Research Program”, PCI Journal, Vol. 50:6, 2005, pp. 14-31.

16. Mander, J. B., Priestley, M. J. N., and Park, R., “Theoretical Stress-Strain Model for Confined Concrete”, ASCE Journal of Structural Engineering, Vol. 114:8, 1988, pp. 1804-1826.

17. Walsh, K. Q., Kurama, Y., "Effects of loading conditions on the behavior of unbounded posttensioning strand-anchorage systems”. PCI Journal, Vol. 57:1, 2012, pp. 76-96.

18. Rodriguez, M. E., Restrepo, J. I., and Carr, A. J., "Earthquake-induced Floor Horizontal Accelerations in Buildings”, Earthquake Engineering \& Structural Dynamics, Vol. 31:3, 2002, pp. 693-718.

19. Wiebe, L. and Christopoulos, C., “Characterizing acceleration spikes due to stiffness changes in nonlinear systems”, Earthquake Engineering and Structural Dynamics, Vol. 39, 2010, pp. 1653-1670.

20. Dolce, M. and Cardone, D., "Seismic protection of light secondary systems through different base isolation systems”, Journal of Earthquake Engineering, Vol. 7:2, 2003, pp. 223-250.

21. Binns, R. D. and Mygind, H. S., "The use of electrical resistance strain gauges, and the effect of aggregate size on gauge length in connection with the testing of concrete”. Magazine of Concrete Research, Vol.1:1, 1949, pp. 35-39. 


\title{
DYNAMIC BEHAVIOR OF ROCKING AND HYBRID CANTILEVER WALLS IN A PRECAST CONCRETE BUILDING
}

\author{
Andrea Belleri, Matthew J. Schoettler, José I. Restrepo and Robert B. Fleischman
}

\section{TABLES AND FIGURES}

\section{List of Tables:}

Table 1 - Wall idealized bilinear response points.

\section{List of Figures:}

Fig. 1 - Rocking and hybrid walls.

Fig. 2 - Half-scale, three-story, precast concrete structure tested at UCSD and close up view of the base of the South wall at peak rotation during BER-DBE test.

Fig. 3 - Model structure plan view.

Note: $25.4 \mathrm{~mm}=1 \mathrm{in}$;; prototype structure dimensions = 2x shown dimensions.

Fig. 4 - Elevation showing precast post-tensioned cantilever wall.

Note: $25.4 \mathrm{~mm}=1 \mathrm{in}$;; prototype structure dimensions $=2 \mathrm{x}$ shown dimensions.

Fig. 5 - North wall base cross section.

Note: $25.4 \mathrm{~mm}=1 \mathrm{in}$;; prototype structure dimensions $=2 \mathrm{x}$ shown dimensions.

Fig. 6 - Pseudo-acceleration response spectra of input ground motions.

Notes: ratio $P G A_{m} / P G A_{p}=1.855$; $\xi=5 \%$; ground motion measured during test.

Fig. 7 - North wall sensor distribution. Note: $25.4 \mathrm{~mm}=1 \mathrm{in}$.

Fig. 8 - North wall normalized moment-rotation and shear rotation response.

Fig. 9 - North wall normalized effective height.

Fig. 10 - North wall and adjacent floor units horizontal acceleration.

Fig. 11 - North wall vertical acceleration.

Fig. 12 - Required coefficient of friction to avoid sliding.

Fig. 13 - North wall neutral axis variation at selected wall base rotations.

Fig. 14 - North wall maximum compressive concrete strains at toe. 
1 Fig. 15 - North wall maximum compressive concrete strains at toe at selected wall base 2 rotations. 


\section{$1 \quad$ Table 1}

\begin{tabular}{ccc}
\hline \hline & KNX & SEA - BER \\
\hline \hline$\Lambda$ & 0 & 0.258 \\
\hline$\theta_{y}$ (milliradian) & 0 & 0.62 \\
\hline$M_{n} /\left(f^{\prime}{ }_{c} t_{w} l_{w}{ }^{2}\right)$ & 0.0086 & 0.0186 \\
\hline$V_{n} / W$ & 0.115 & 0.247 \\
\hline$\theta_{0}($ milliradian $)$ & 30.3 & 24.8 \\
\hline$M_{0} /\left(f_{c}{ }_{c} t_{w} l_{w}{ }^{2}\right)$ & 0.0268 & 0.0354 \\
\hline$V_{0} / W$ & 0.360 & 0.470 \\
\hline \hline
\end{tabular}

2

Table 1 - Wall idealized bilinear response points.

4 


\section{$1 \quad$ Fig. 1}

(a)

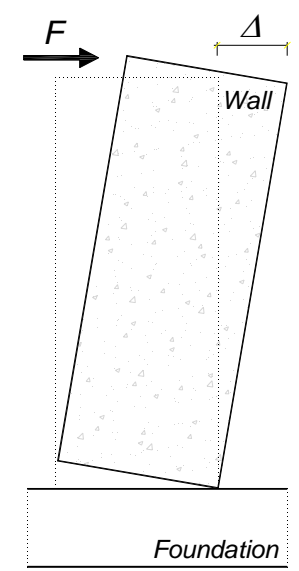

(b)

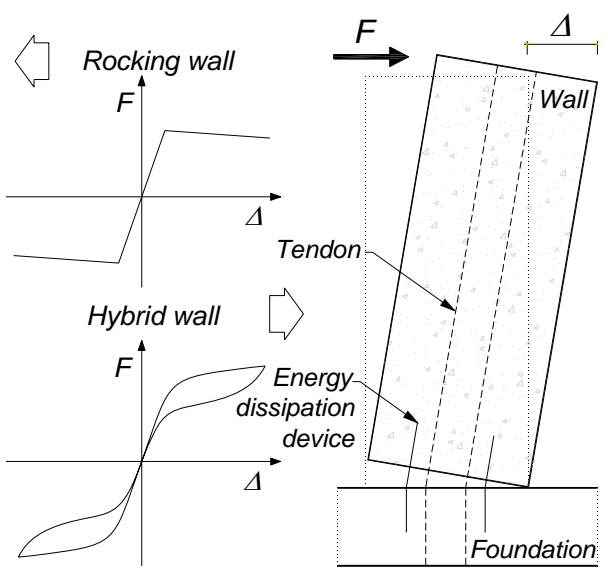

Fig. 1 - Rocking and hybrid walls.

4 


\section{$1 \quad$ Fig. 2}

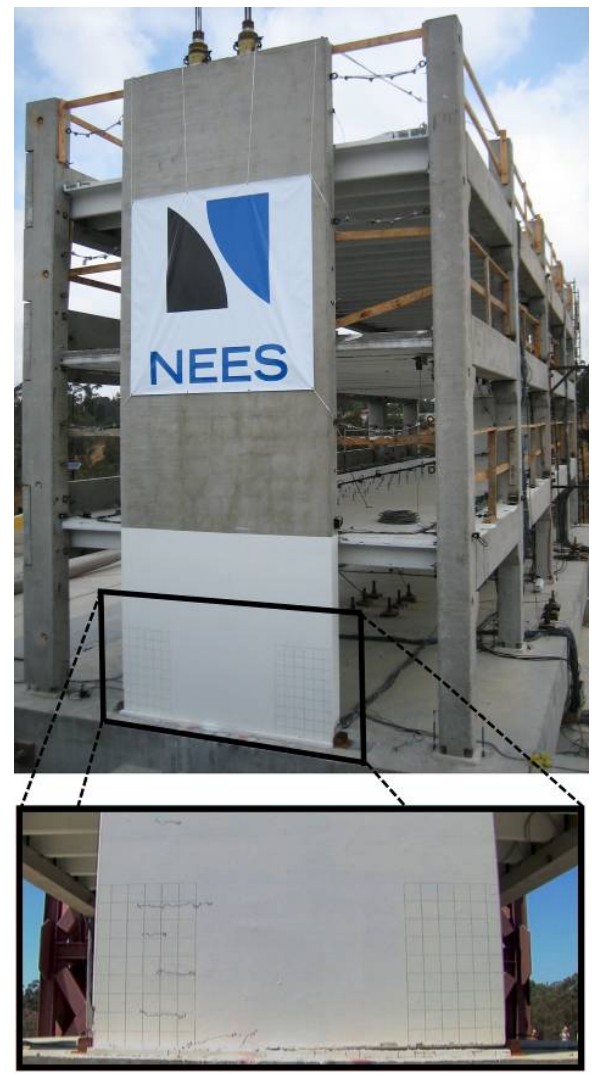

3 Fig. 2 - Half-scale, three-story, precast concrete structure tested at UCSD and close up view

4 of the South wall base at peak rotation during BER-DBE test. 
1 Fig. 3

2

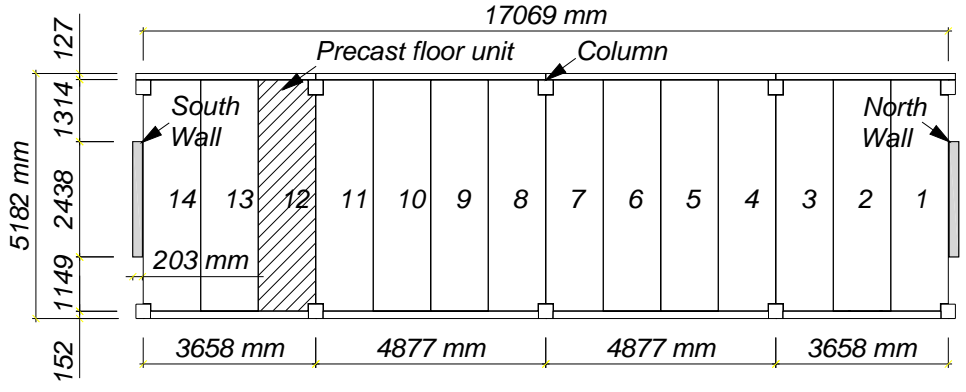

3

Fig. 3 - Model structure plan view.

4

Note: $25.4 \mathrm{~mm}=1 \mathrm{in}$; prototype structure dimensions $=2 \mathrm{x}$ shown dimensions. 
$1 \quad$ Fig. 4

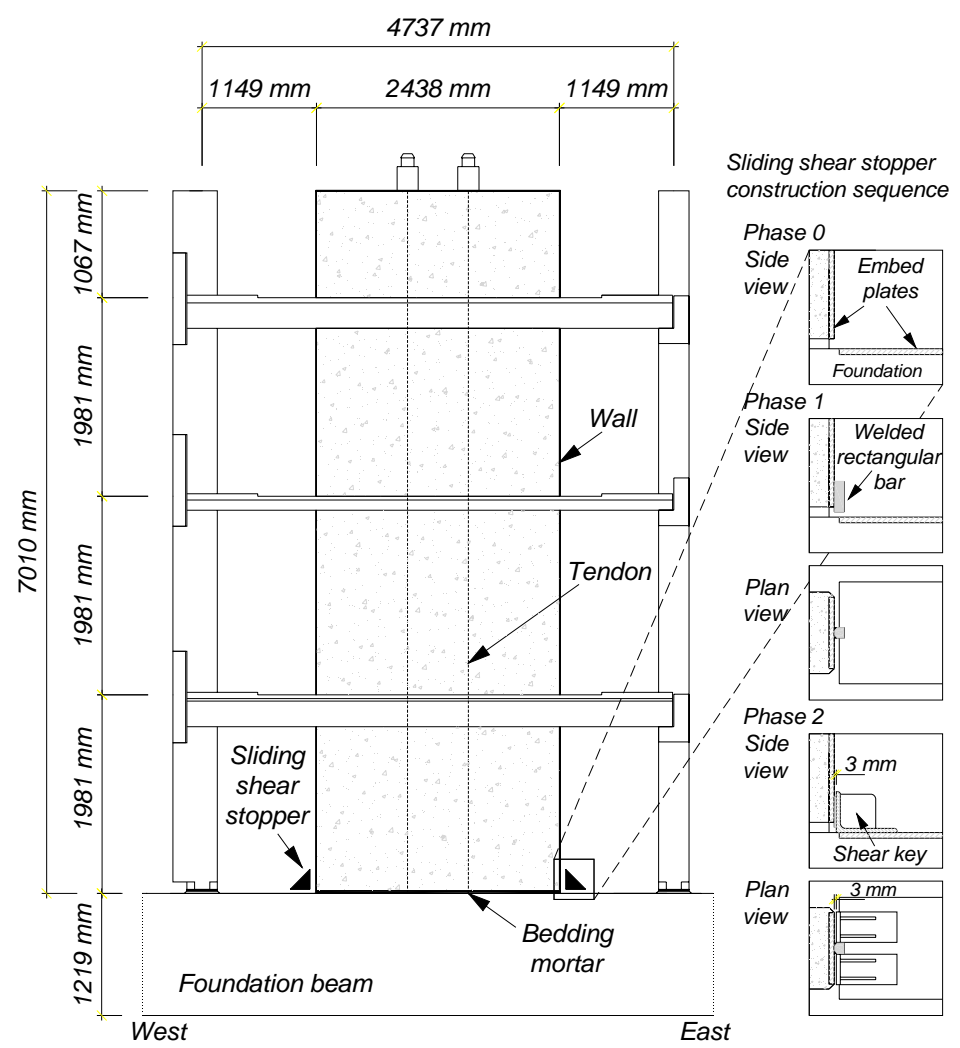

Fig. 4 - Elevation showing precast post-tensioned cantilever wall. 


\section{Fig. 5}

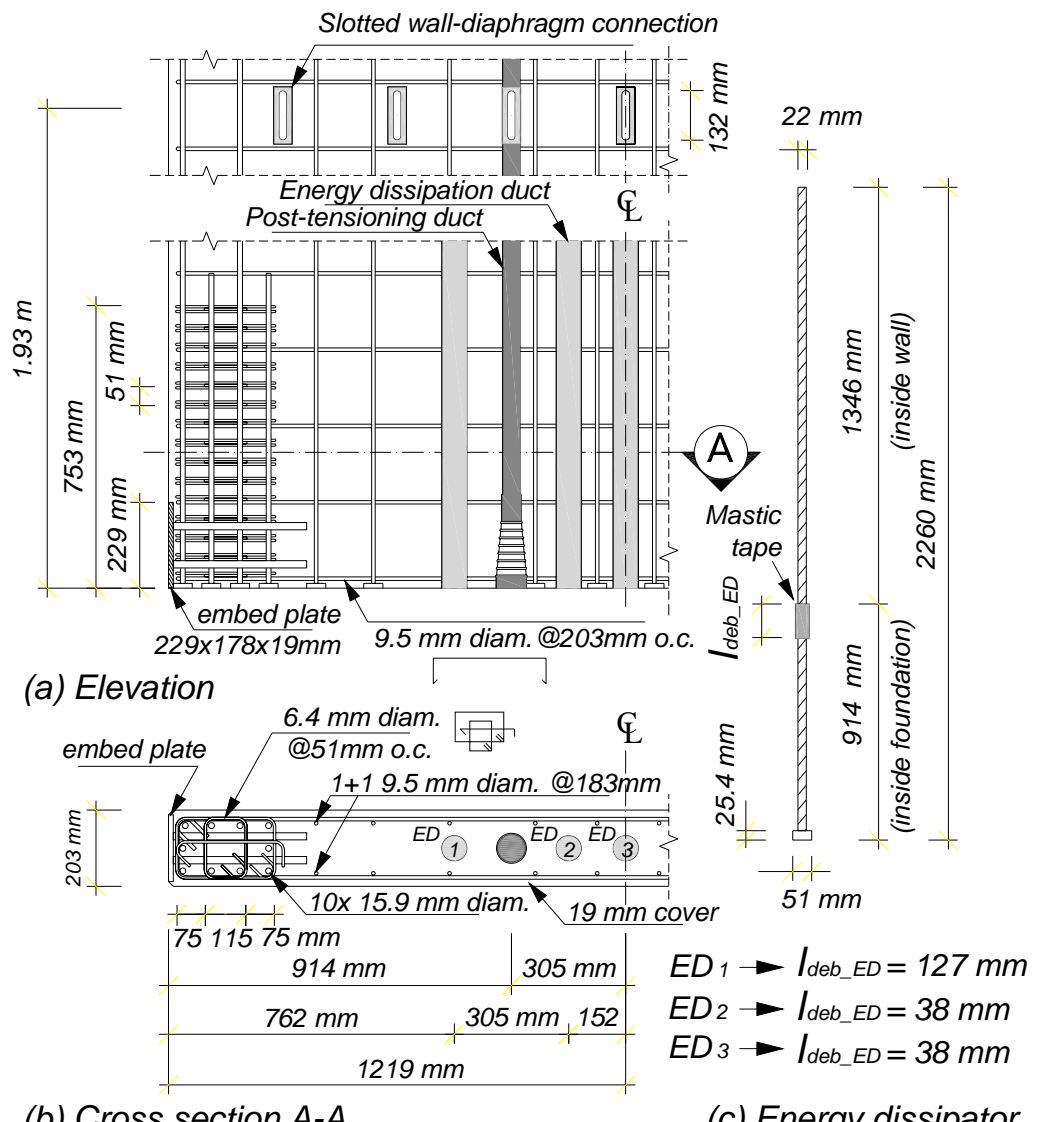

Fig. 5 - North wall base cross section.

Note: $25.4 \mathrm{~mm}=1$ in.; prototype structure dimensions $=2 \mathrm{x}$ shown dimensions. 


\section{Fig. 6}

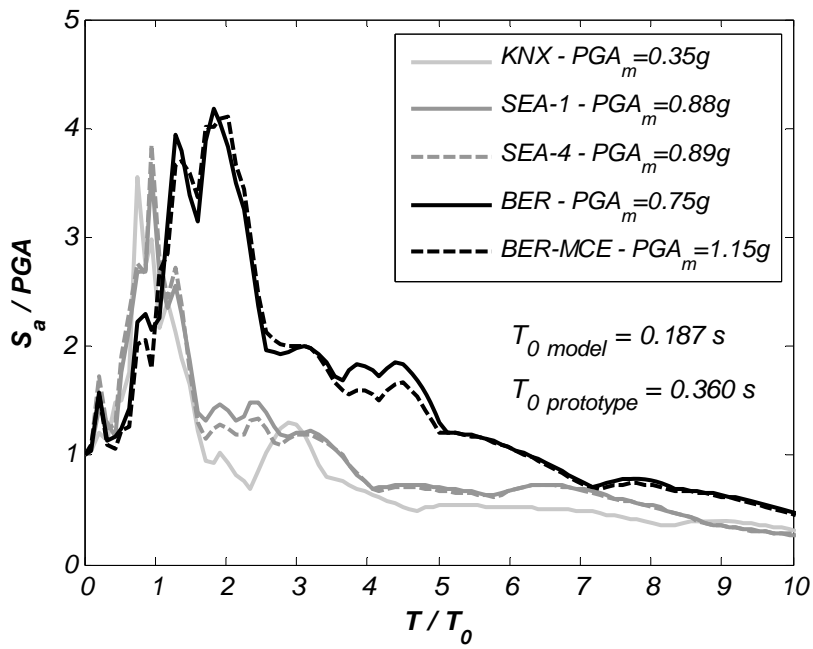

Fig. 6 - Pseudo-acceleration response spectra of input ground motions.

Notes: $P G A_{m} / P G A_{p}=1.855 ; \xi=5 \%$; ground motion measured during test. 


\section{$1 \quad$ Fig. 7}

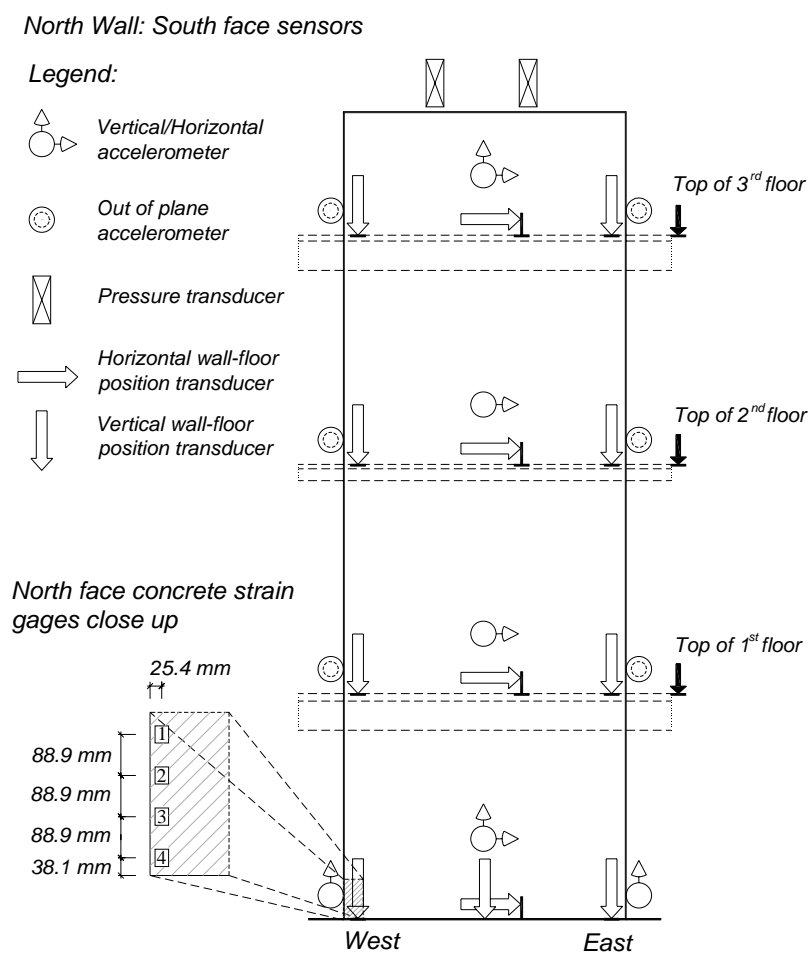

Fig. 7 - North wall sensor distribution. Note: $25.4 \mathrm{~mm}=1 \mathrm{in}$. 
Fig. 8
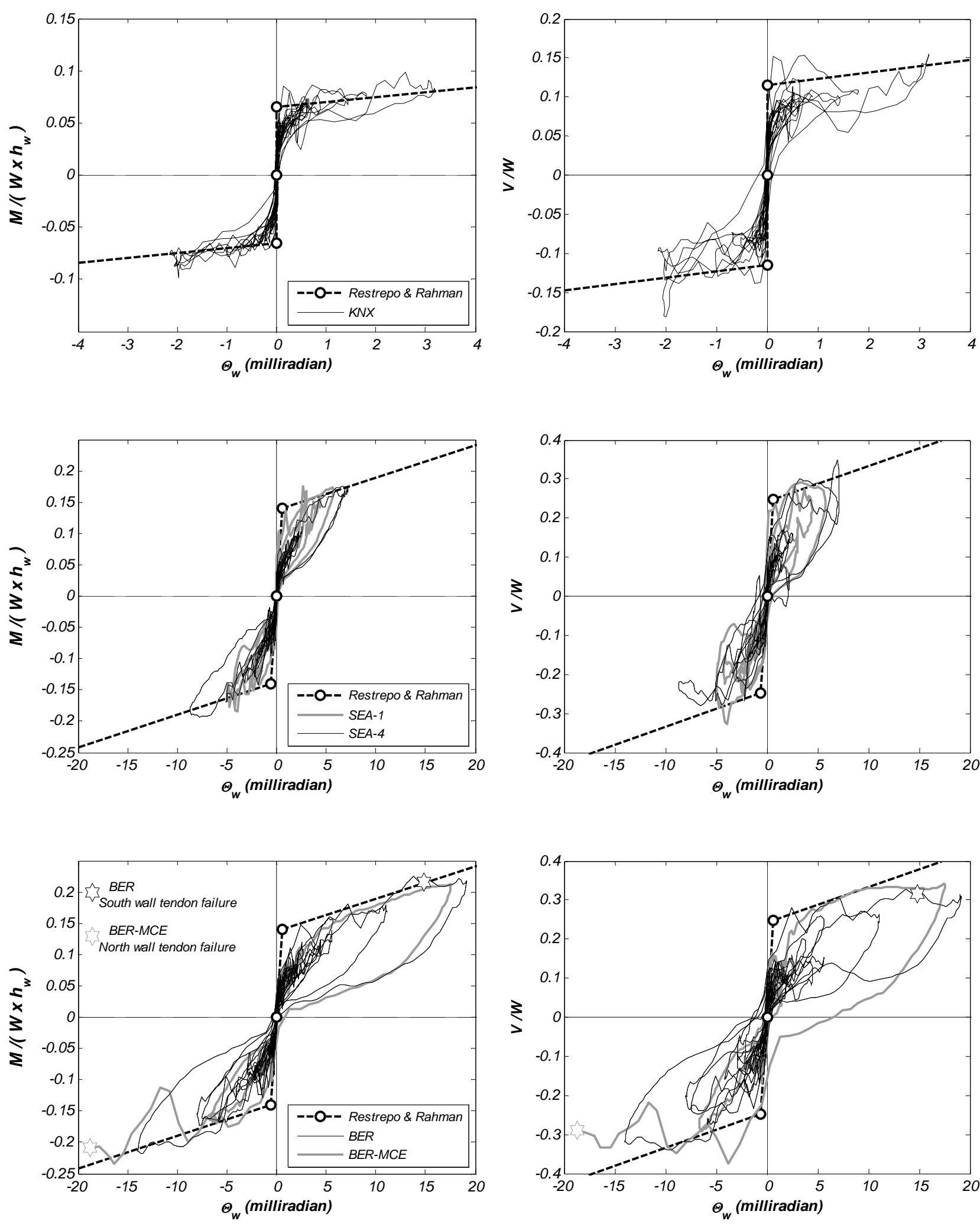

Fig. 8 - North wall normalized moment-rotation and shear-rotation response. 
Fig. 9

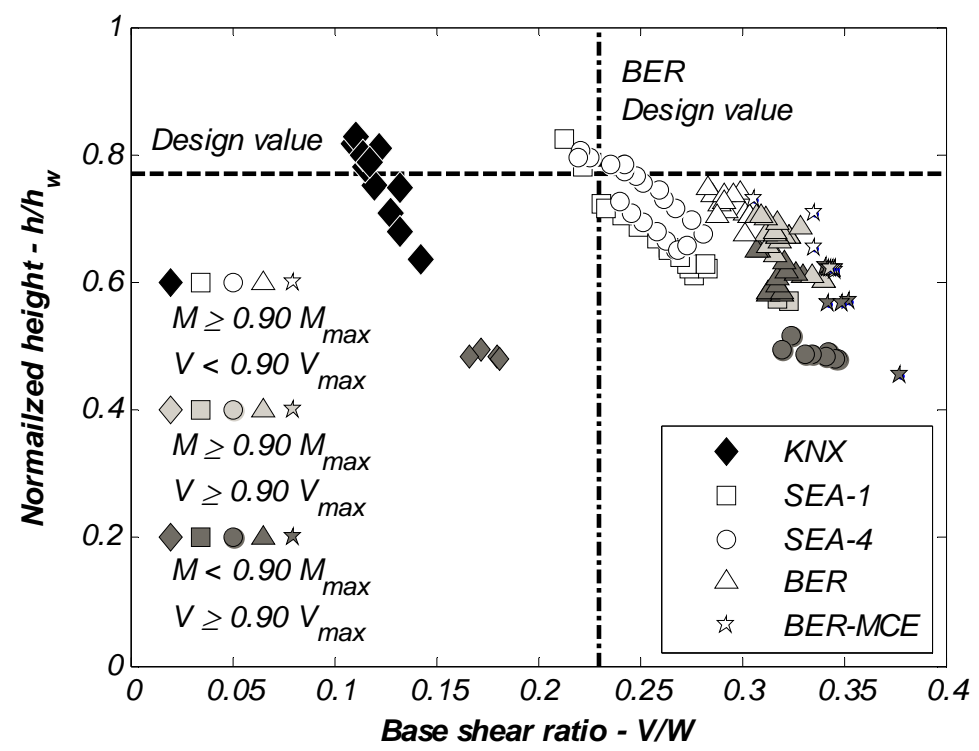

Fig. 9 - North wall normalized effective height. 
Fig. 10
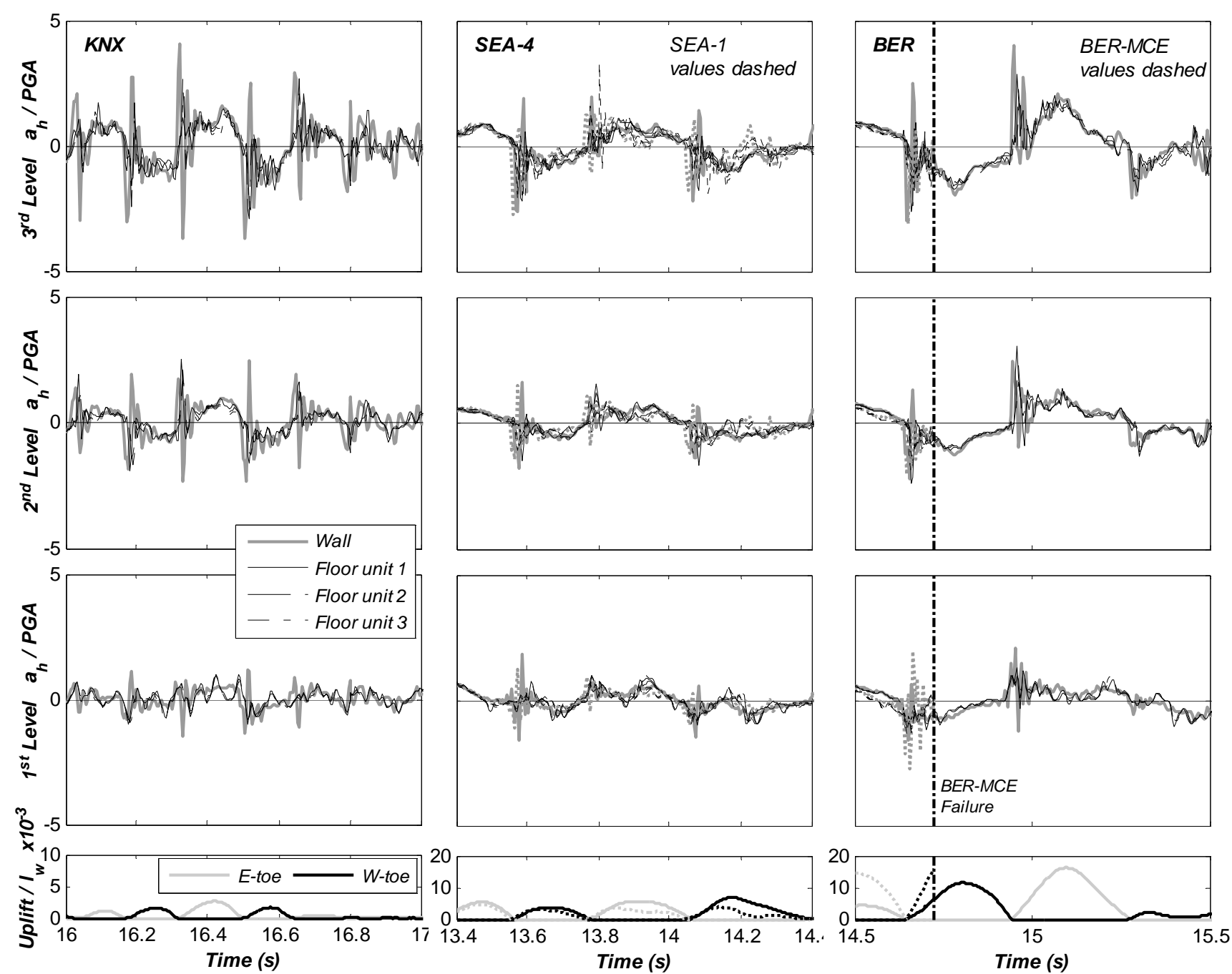

Fig. 10 - North wall and adjacent floor units horizontal acceleration. 


\section{$1 \quad$ Fig. 11}
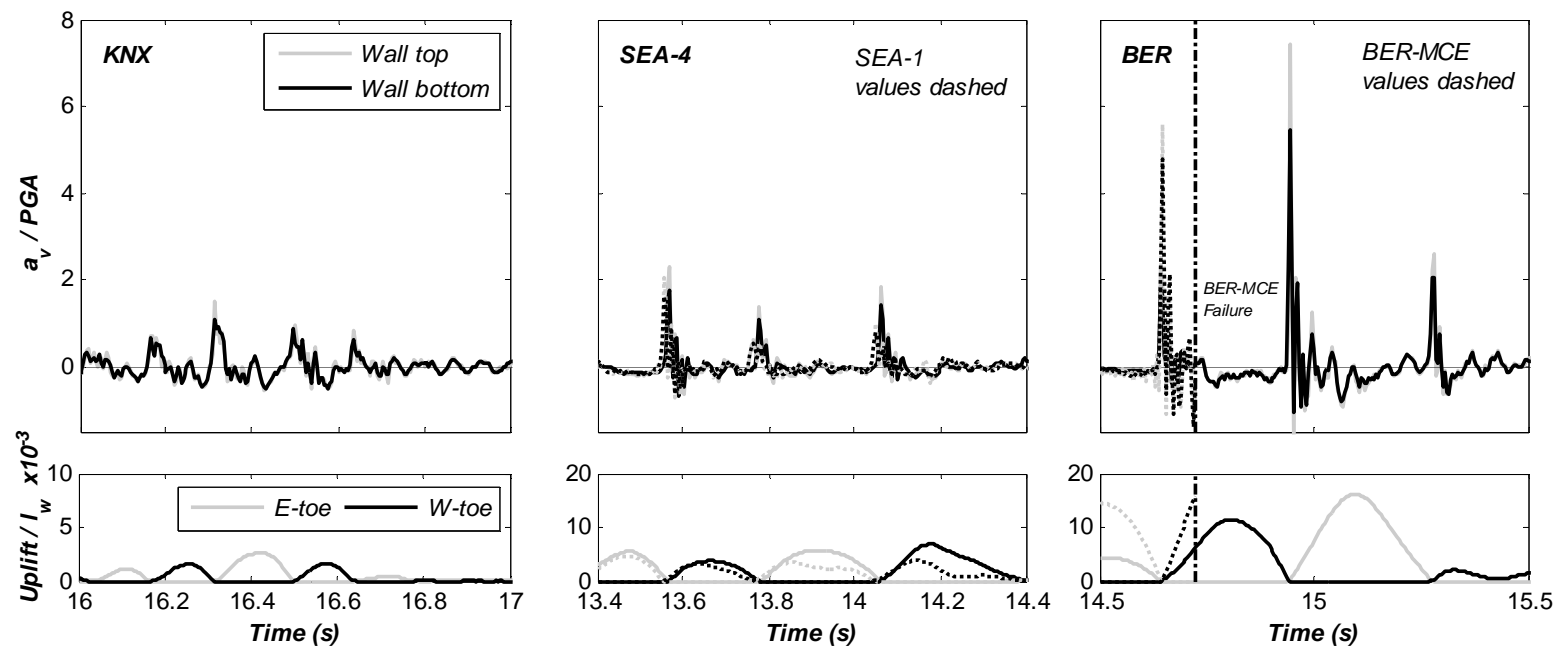

Fig. 11 - North wall vertical acceleration. 


\section{$1 \quad$ Fig. 12}

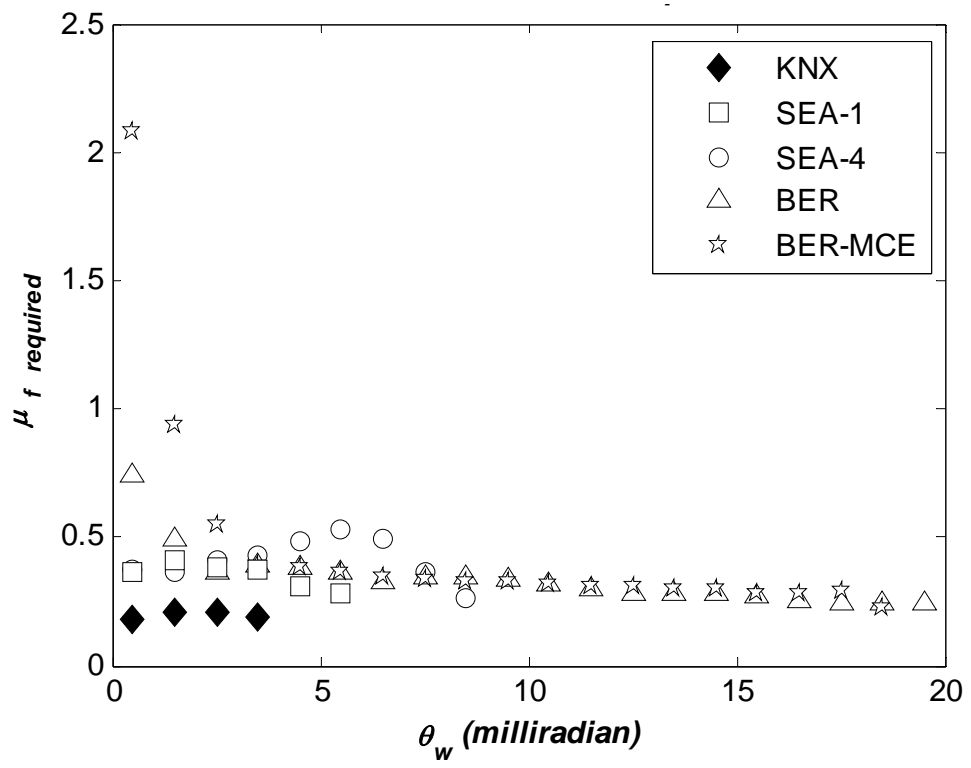

Fig. 12 - Required coefficient of friction to avoid sliding. 


\section{$1 \quad$ Fig. 13}

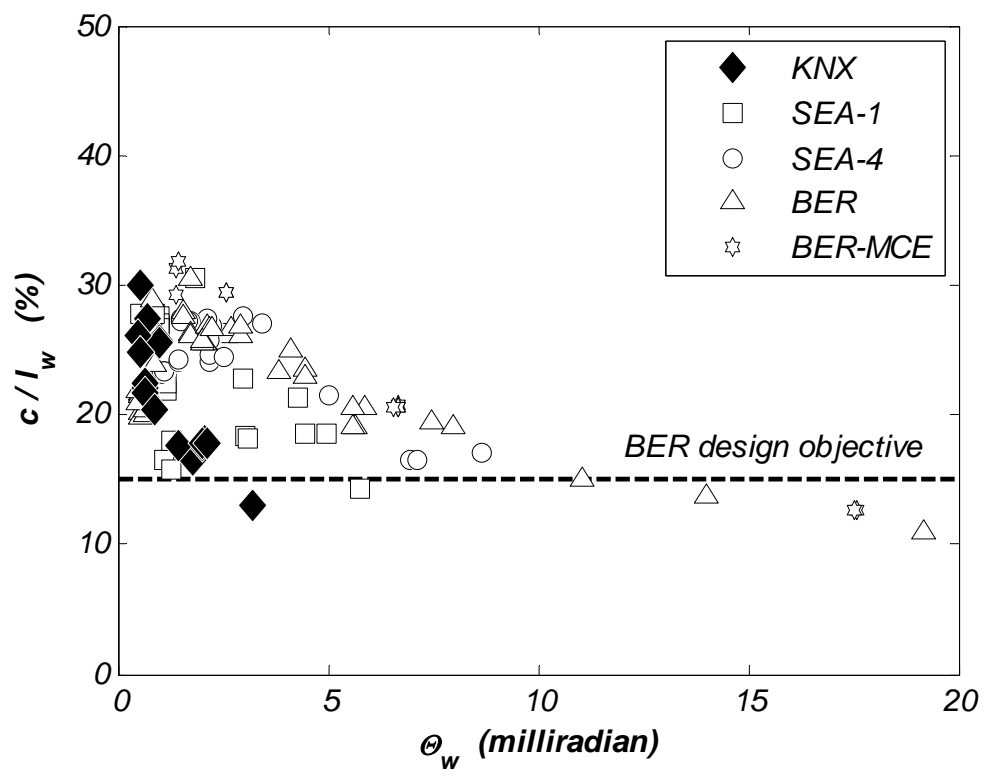

3

Fig. 13 - North wall neutral axis variation at selected wall base rotations.

4 


\section{$1 \quad$ Fig. 14}

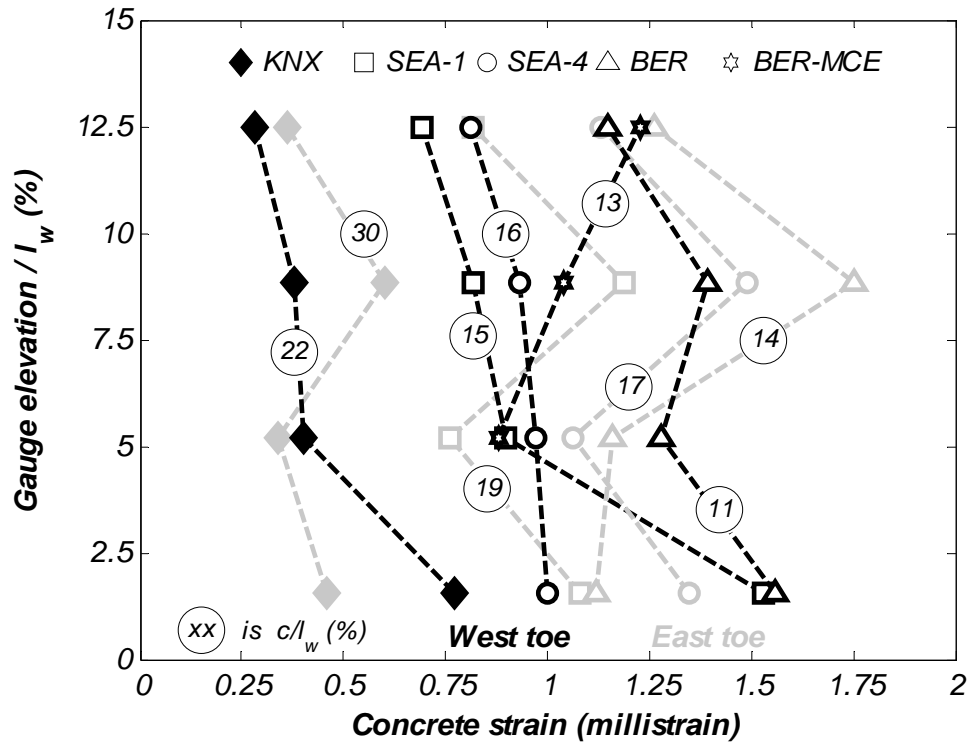

Fig. 14 - North wall maximum compressive concrete strains at toe. 


\section{$1 \quad$ Fig. 15}

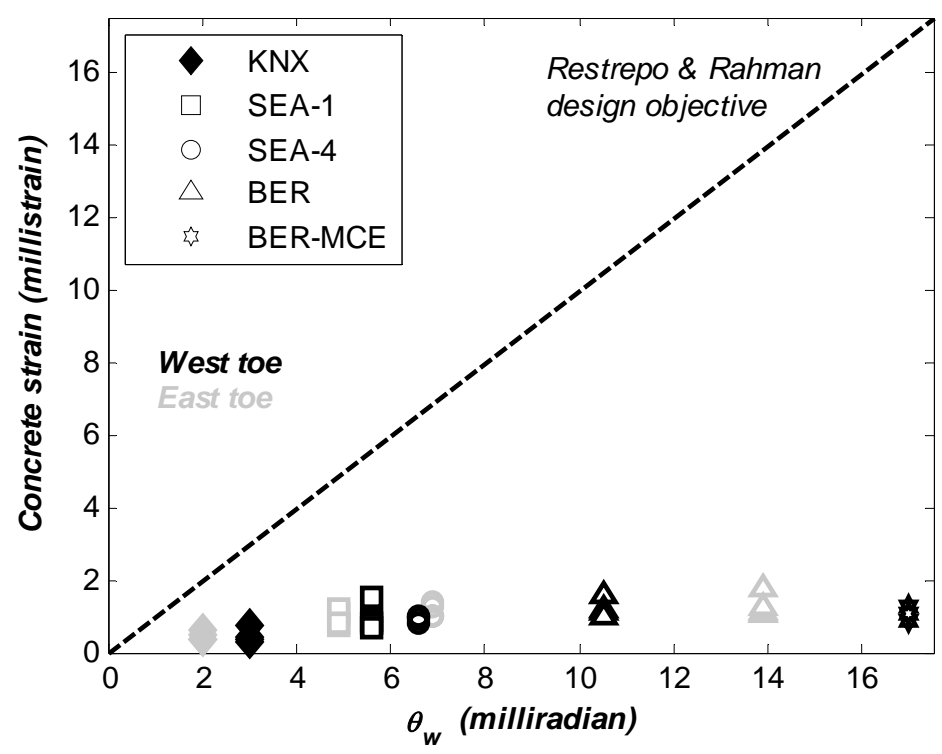

3 Fig. 15 - North wall maximum compressive concrete strains at toe at selected wall base rotations. 
2

3

4

5

6

7

8

9

10

APPENDIX A

11

RELEVANT MECHANICAL AND GEOMETRICAL PROPERTIES

12 
1 Table A-1

\begin{tabular}{|c|c|}
\hline \multicolumn{2}{|c|}{ "Unconfined region } \\
\hline Longitudinal reinforcement ratio & $0.38 \%$ \\
\hline Transverse reinforcement ratio & $0.34 \%$ \\
\hline \multicolumn{2}{|c|}{ Confined region } \\
\hline Cross section & 305x203 mm (12x8 in) \\
\hline Vertical extension & $762 \mathrm{~mm}$ (30 in) \\
\hline Longitudinal reinforcement ratio & $3.22 \%$ \\
\hline Transverse reinforcement ratio & $\begin{array}{l}1.13 \% \text { (Through depth) } \\
1.12 \% \text { (Through thickness) }\end{array}$ \\
\hline Effective area ratio $-\mathrm{A}_{\mathrm{eff}} / \mathrm{A}_{\text {core }}$ & $80 \%$ \\
\hline $\begin{array}{l}\text { Volume ratio of transverse } \\
\text { reinforcement and confined core }-\rho_{\mathrm{s}}\end{array}$ & $2.29 \%$ \\
\hline
\end{tabular}

Table A-1 - Test wall confined and un-confined region details. 
Table A-2

\begin{tabular}{|c|c|c|c|c|c|c|}
\hline \multicolumn{7}{|c|}{ Concrete and grout properties } \\
\hline & \multirow{3}{*}{$\begin{array}{l}\text { Age } \\
\text { days }\end{array}$} & \multirow{3}{*}{$\begin{array}{l}\text { Strength } \\
\text { MPa (ksi) }\end{array}$} & \multicolumn{2}{|c|}{ Test beginning } & \multicolumn{2}{|c|}{ Test end } \\
\hline & & & Age & Strength & Age & Strength \\
\hline & & & days & MPa (ksi) & days & MPa (ksi) \\
\hline Wall concrete & 28 & $54(7.76)^{\mathrm{a}}$ & 98 & $51(7.4)^{b}$ & 126 & $55(8)^{b}$ \\
\hline Base joint grout & 35 & $48(7.0)^{b}$ & 82 & $49(7.1)^{b}$ & 120 & $48(6.9)^{b}$ \\
\hline ED grout: foundation & 28 & $49(7.1)^{\mathrm{a}}$ & 87 & $62(9.0)^{a}$ & 115 & $42(6.1)^{a}$ \\
\hline ED grout: wall & 13 & $35(5.0)^{b}$ & $=$ & $=$ & 36 & $38(5.5)^{b}$ \\
\hline \multicolumn{7}{|c|}{ Energy dissipator properties } \\
\hline $\begin{array}{c}\text { Yield strengt } \\
\text { MPa (ksi) }\end{array}$ & & \multicolumn{3}{|c|}{$\begin{array}{l}\text { Ultimate tensile strength } \\
\text { MPa (ksi) }\end{array}$} & \multicolumn{2}{|c|}{$\begin{array}{c}\text { Strain at ultimate tensile } \\
\text { strength }\end{array}$} \\
\hline $490(71.1)^{\mathrm{a}}$ & & \multicolumn{3}{|c|}{$673(97.6)^{a}$} & \multicolumn{2}{|c|}{$12.3 \%^{\mathrm{c}}$} \\
\hline
\end{tabular}

${ }^{a}$ Average of two cylinder tests

${ }^{\mathrm{b}}$ Average of three cylinder tests

${ }^{\mathrm{c}}$ Lowest value obtained from two coupons

$=$ not available

6

Table A-2 - Relevant material mechanical properties. 
2

3

4

5

6

7

8

9

10

APPENDIX B

11

NOTATION

12 
1 The following symbols are used in the paper:

$2 a_{v} \quad$ vertical upward acceleration excluding acceleration due to gravity (g)

$3 a_{h} \quad$ horizontal acceleration (g)

$4 \quad A_{\text {core }}$ confined concrete core area taken as hoop centerline distance $\left(\mathrm{mm}^{2}\right)$

$5 \quad A_{\text {eff }} \quad$ confined concrete core effective area $\left(\mathrm{mm}^{2}\right)$

6 BER Berkeley - CA

$7 \quad c \quad$ neutral axis depth (m)

$8 \quad d_{b} \quad$ energy dissipation bar diameter (mm)

9 DBE Design Basis Earthquake

10 ED Energy dissipator

$11 f_{c} \quad$ specified compressive strength for concrete (MPa)

$12 f_{c c}^{\prime} \quad$ compressive strength for confined concrete (MPa)

$13 f_{y h} \quad$ yield strength of transverse reinforcement (MPa)

$14 \quad F_{\text {ed }} \quad$ ultimate tensile force of energy dissipator $(\mathrm{kN})$

$15 \quad F_{p 0} \quad$ prestressing force in tendons after losses $(\mathrm{kN})$

$16 \quad F_{p p} \quad$ tensile force in post-tensioning tendon corresponding to nominal limit of proportionality

$17 \quad(\mathrm{kN})$

$18 f_{p u} \quad$ nominal ultimate tensile strength of post-tension tendon (MPa)

$19 g \quad$ acceleration of gravity $\left(\mathrm{m} / \mathrm{s}^{2}\right)$

$20 \quad h_{w} \quad$ wall height $(\mathrm{m})$

21 KNX Knoxville - TN

$22 \quad l_{E D} \quad$ energy dissipator distance from wall edge (m)

$23 l_{\text {deb_ED }}$ energy dissipator debonded length (m)

$24 \quad l_{w} \quad$ wall length (m)

25 MCE Maximum Considered Earthquake

$26 M_{0} \quad$ overturning moment at yielding of critical tendon $(\mathrm{kNm})$ 
$1 \quad M_{n} \quad$ overturning moment at apparent yield point $(\mathrm{kNm})$

$2 \quad M_{p r} \quad$ probable flexural strength for the wall foundation interface ${ }^{7}(\mathrm{kNm})$

$3 \quad$ PGA peak ground acceleration (g)

$4 \quad P G A_{p}$ peak ground acceleration in prototype space (g)

$5 \quad P G A_{m}$ peak ground acceleration in model space (g)

$6 \quad P_{u} \quad$ axial load due to gravity loads $(\mathrm{kN})$

$7 \quad S_{a} \quad$ pseudo acceleration (g)

8 SEA Seattle - WA

$9 \quad t_{w} \quad$ wall thickness (m)

$10 \quad$ base shear $(\mathrm{kN})$

$11 V_{\text {capacity }\left(\theta_{\mathrm{w}}=0\right)}$ base shear capacity at 0 wall base rotation (gap opening) $(\mathrm{kN})$

$12 V_{\text {demand }\left(\theta_{w}=0\right)} \quad$ base shear demand at 0 wall base rotation (gap opening) $(\mathrm{kN})$

$13 V_{\text {demand, max }}$ maximum base shear demand $(\mathrm{kN})$

$14 V_{0} \quad$ base shear at yielding of critical tendon $(\mathrm{kNm})$

$15 \quad V_{n} \quad$ base shear at apparent yield point $(\mathrm{kNm})$

16 model structure weight $(\mathrm{kN})$

$17 \alpha \quad$ ratio between base shear demand at zero gap opening and maximum base shear demand

$18 \varepsilon_{c u} \quad$ ultimate confined concrete compressive strain $(\mathrm{mm} / \mathrm{mm})$

$19 \varepsilon_{U T S} \quad$ ultimate energy dissipator strain $(\mathrm{mm} / \mathrm{mm})$

$20 \mu_{f} \quad$ coefficient of friction

$21 \Lambda=F_{e d} /\left(P_{u}+F_{p p}+F_{e d}\right)$ energy dissipation index

$22 \theta_{0} \quad$ wall base rotation (gap opening) at yielding of critical tendon (milliradian)

$23 \theta_{w} \quad$ wall base rotation (gap opening) (milliradian)

$24 \theta_{w, \text { des }} \quad$ wall base rotation (gap opening) design value (milliradian)

$25 \theta_{y} \quad$ wall base rotation (gap opening) at apparent yield point (milliradian) 
$1 \quad \theta^{\prime} \quad$ wall base rotational velocity $(\mathrm{rad} / \mathrm{sec})$

$2 \rho_{s} \quad$ volume ratio of transverse reinforcement and confined core $\left(\mathrm{mm}^{3} / \mathrm{mm}^{3}\right)$

$3 \quad \xi \quad$ viscous damping ratio 